
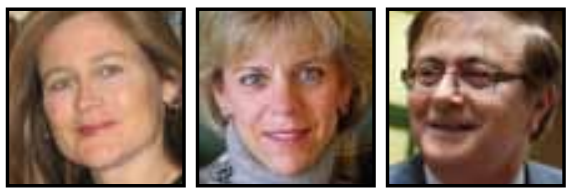

\title{
Teaching With Electronic Portfolios to Develop 21st Century Literacies
}

\author{
Elizabeth J. Meyer, California Polytechnic State University \\ Anne Wade, Concordia University \\ Philip C. Abrami, Concordia University
}

\section{ABSTRACT}

This article introduces an electronic portfolio, ePEARL, and how it has been used in classrooms to promote 21st century literacies. Using NCTE's 21st Century Literacies framework, the authors provide examples of student work and classroom assignments to demonstrate how an electronic portfolio can support teachers integrating this framework and developing these skills in pedagogically meaningful ways.

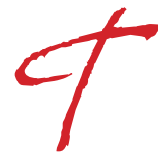

oday the grade four students were working on a group science project: the design of an "Insulating Machine." To prepare for this lesson using electronic portfolios, the teacher had taken digital photos of the machines each group had already built and saved them on a USB key. A technology consultant was working with the teacher in class this day, so the consultant spent time with each group showing the students how to download the image files, and then upload them to the correct location in their ePortfolio. As the students waited for their turns with the USB key, they worked in groups inputting the text describing this project in their ePortfolios. One person was working in their portfolio and once the data was fully entered they were able to "share" the artifact with their group members for inclusion in their own ePortfolios.

Before creating their insulating machines, the students completed paperand-pencil planning sheets that included: a description of the assignment, the group's goals, and specific strategies they had planned to use to successfully satisfy 
the criteria for the project (Figure 1). The groups referred to their planning sheets as they entered the text into each corresponding field of their ePortfolios. The students then input the temperature data they had recorded earlier, discussed their findings, and attached the photos that showed the machine they had built (Figure 2). This lesson is just one of many examples of how elementary teachers are using ePortfolios to help promote 21st century literacies across the curriculum. This article provides detailed examples from three elementary classrooms of how the use of an electronic portfolio can help support teachers in their efforts to teach media literacy, information and computing technology (ICT), and related language arts skills that are often described as "21st Century Literacies."

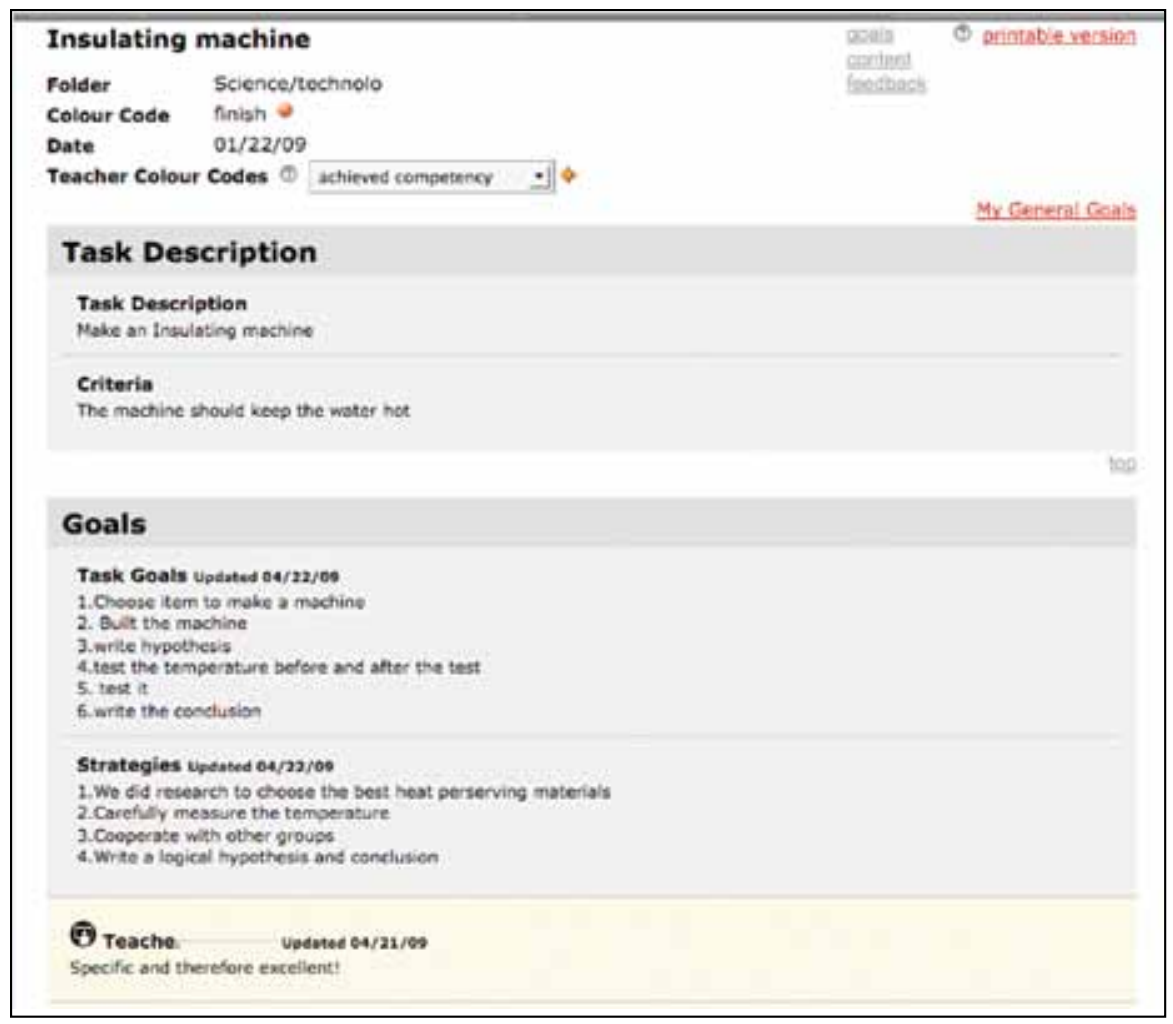

Fig. 1: Insulating machine project: planning 


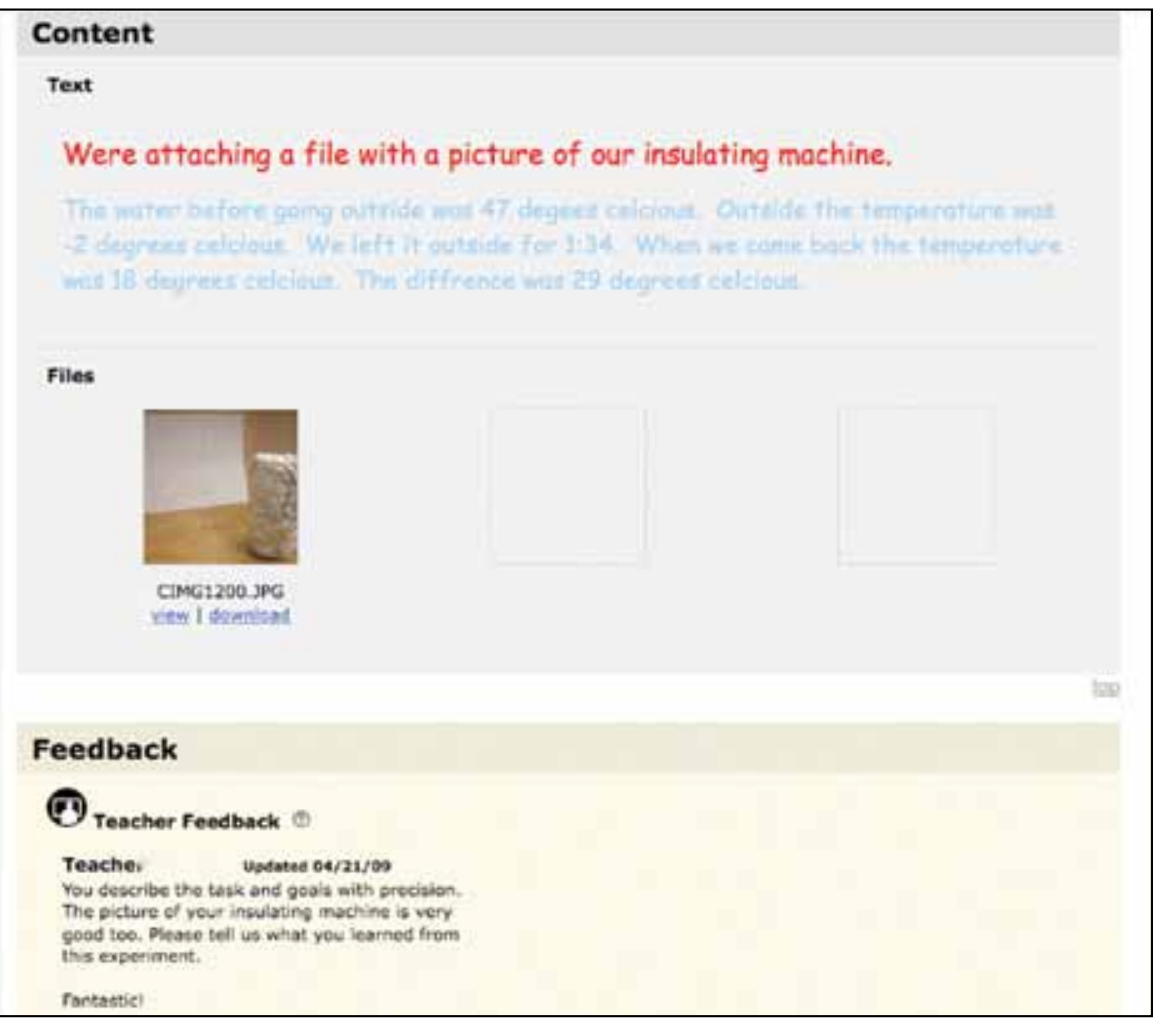

Fig. 2: Insulating machine project: content and teacher feedback

\section{1st Century Literacies: Definitions and Framework}

In 2008, the National Council of Teachers of English released a new framework for literacy education. This framework provides a working definition for 21st century literacies and how the evolving demands of new technologies and communications are able to inform new literacies education.

Literacy has always been a collection of cultural and communicative practices shared among members of particular groups. As society and technology change, so does literacy. Because technology has increased the intensity and complexity of literate environments, the twenty-first century demands that a literate person possess a wide range of abilities and competencies, many literacies. These literaciesfrom reading online newspapers to participating in virtual classrooms-are multiple, dynamic, and malleable. As in the past, they are inextricably linked with particular 
histories, life possibilities, and social trajectories of individuals and groups. Twentyfirst century readers and writers need to:

- Develop proficiency with the tools of technology

- Build relationships with others to pose and solve problems collaboratively and cross-culturally

- Design and share information for global communities to meet a variety of purposes

- Manage, analyze, and synthesize multiple streams of simultaneous information

- Create, critique, analyze, and evaluate multimedia texts

- Attend to the ethical responsibilities required by these complex environments (NCTE, 2008)

This framework is written in such a way to help teachers "explore and implement 21st century skills," reflect on their practice, and begin conversations about the possibilities that this framework holds to best meet the evolving needs of students in schools today (Bass, Sibberson, Hayes, McGraw, \& White, 2010, pp. 390-391). This article will present the work of three elementary school teachers who integrated an electronic portfolio, ePEARL, in their classrooms, and discuss how this tool facilitated the process of integrating 21 st century literacy skills into their classroom practices.

An electronic portfolio (EP) is a digital container capable of storing visual and auditory content including text, images, video, and sound. EPs may also be learning tools not only because they organize content but also because they are designed to support a variety of pedagogical processes including reflecting on one's own learning and providing feedback to peers to stimulate their own reflections (Abrami \& Barrett, 2005; Wade, Abrami, \& Sclater, 2005). This reflection process is a key element in students' learning and effective communication between students is an important part of this process. EPs have three broad purposes: process, presentation, and assessment. For assessment purposes, EPs can be used to display examples of students' authentic activity and are especially useful for formative purposes, showing progress over time; while presentation portfolios are used to represent students' most important works-however the teacher and student choose to define "important." The focus of this article is on using EPs as process portfolios as they have great potential for supporting and demonstrating learning of the 21st century literacy skills mentioned above. 
EPs may be designed as process (or learning) portfolios supporting how users learn through embedded structures and strategies. A process EP is a purposeful collection of student work that tells the story of a student's effort, progress and/ or achievement in one or more areas (Arter \& Spandel, 1992; Maclsaac \& Jackson, 1994). Process portfolios are personal learning management tools. They are meant to encourage individual improvement, personal growth and development, and a commitment to lifelong learning.

Process EPs are gaining in popularity for multiple reasons. They provide multimedia display and assessment possibilities for school and work contexts allowing the use of a variety of tools to demonstrate and develop understanding-especially advantageous for at-risk children whose competencies may be better reflected through these authentic tasks. At the same time, by engaging these learners, their deficiencies in core competencies such as reading, writing, and general learning skills may be overcome. Process EPs scaffold attempts at knowledge construction by supporting planning, reflection, refinement, conferencing, and other processes of selfregulation, important skills for lifelong learning, and learning how to learn (Meyer, Abrami, Wade, Aslan, \& Deault, 2010). They are superior for cataloguing and organizing learning materials, better illustrating the process of learner development. Many EPs are web-based, so they can also provide remote access encouraging anywhere, anytime learning and easier input from peers, parents, and educators, consolidating feedback through a single electronic container. In this regard, they may be used to foster communication between teacher-student, student-student, and child-parent throughout the learning process, which can support their abilities to "manage, analyze, and synthesize multiple streams of simultaneous information" as well as "build relationships with others to pose and solve problems collaboratively and crossculturally" (NCTE, 2008).

\section{Research Context and Methods}

The research presented here represents a subset of a larger study. Participants in the full study were 21 teachers from elementary schools (grades 4-6), and their students $(n=483)$ from nine urban and rural English school boards in Quebec and Alberta who participated during the 2008-2009 school year which was the final year of a three-year study. All experimental teachers $(n=9)$ received at least a halfday of training on the use of ePEARL from the research centre's staff and follow-up support including lesson plans and job aids, an online discussion forum (in the form 
of a moderated wiki), as well as in-class observations and model lessons during the school year. In addition, multimedia scaffolding and support for teachers and students are embedded in the tool.

We worked actively with school principals and school board administrators to identify control teachers and their classrooms who would match as closely as possible the experimental teachers and their classrooms. All teachers needed to follow the language arts provincial curriculum requirements. Experimental teachers did so with the aid of ePEARL, while control teachers did not. All teachers were at liberty to decide how the provision of language arts instruction will unfold in their classrooms. There were no special language arts materials provided to either experimental or control teachers by the research team.

The design of the study was a two-group repeated measures design. Teacher and student pretest questionnaire data were collected in SeptemberOctober of 2008. Teacher and student questionnaire post-test data were collected again in May-June of 2009 after ePEARL was used for some part of the school year ranging from 6 to 8 months. In addition to questionnaires, all students completed the constructed response of the Canadian Achievement Test (version 4) in both the fall and the spring to assess their reading and writing skills. This article reports on data collected in three classrooms (AS1, QH6, \& QL9) from three different school districts, which demonstrated the highest levels of implementation of ePEARL based on an analysis of student portfolios, teacher interviews, and classroom observations. These classrooms were chosen in order to illustrate the multiple ways that elementary teachers can integrate instruction based in the 21st century literacies paradigm with the support of an electronic portfolio.

\section{ePEARL: An Example of an e-Portfolio Tool}

The Centre for the Study of Learning and Performance (CSLP) based at Concordia University in Montreal in collaboration with their partner LEARN (http:// www.learnquebec.ca/), developed a web-based, student-centred electronic portfolio software, entitled ePEARL, electronic Portfolio Encouraging Active Reflective Learning, (http://grover.concordia.ca/epearl) that is designed to develop selfregulated learning (Zimmerman, 1989, 2000; Zimmerman \& Tsikalas, 2005), along with improved literacy skills in students. Three levels of ePEARL have been designed for use in early elementary (Level 1), late elementary (Level 2), secondary schools 
(Level 3), and post-secondary education (Level 4). In ePEARL students can: personalize their portfolios; set long- and short-term goals; create new work through use of a text editor and audio recorder, or link to digital files created outside of the tool; reflect on work; share work with classmates; provide and receive feedback from teachers, peers, and parents; edit work; save work under multiple versions and send work to a presentation portfolio. The artifacts index page offers students and teachers an easy way to store, organize, and track the progress of assignments (Figure 3).

ePEARL is designed to promote a student's self-regulated process of learning. The learner-centered software prompts the creation of a home page that reflects each student's personality, interests, and general learning goals for a term or year. One teacher commented that this home page was a great tool to help introduce the new technology to her grade four students. She noted that, "working on their home page was a great way to start off because it involved visuals and it was all about them and setting up a general goal and it was easy, but fun and so that was a nice initiation into the project" (QH6). For each project students also set task goals (G); reflect on works in progress or completed works (R); and give and receive peer, parent, and teacher feedback (C) on the portfolio or on a specific artifact. Teachers may also provide feedback on the student's goal setting and reflection that has occurred within the portfolio. The ePEARL environment guides students through the creation process. The software also offers the ability to attach work completed using other software (A), so it can accommodate any kind of digital work a student creates, including podcasts, videos, PowerPoint files, scanned images, or photographs of threedimensional work.

Before work is created, students are encouraged to set their goals for the assignment, and may attach learning logs, evaluation rubrics, and study plans to keep track of their learning process as it takes place. After the creation of work, sharing with peers or teachers is encouraged so that students may solicit feedback on drafts of work. Students may also reflect on their performance and strategies, and use these to adjust their goals for the next work. Sharing with peers is prompted in the reflection screen (Figure 4). Once students have completed a version of an assignment they are asked if they would like to share this piece with classmates to obtain feedback. Teachers have automatic access to view and enter feedback in all of their students' ePs. This unique feature helps promote collaboration as well as evaluation and feedback skills. It also enables students to view each other's goals, strategies, and completed assignments, which provides additional modeling and scaffolding to their own learning processes. 
The Presentation folder within ePEARL is where students collect selected important artifacts. This provides a cumulative area where artifacts are carried over to the next level of the software and acts as an archive of stored work during a student's educational career. The selection process allows students to reflect on why they feel an artifact belongs in their presentation folder, its relationship to other work, and on their own advancements.

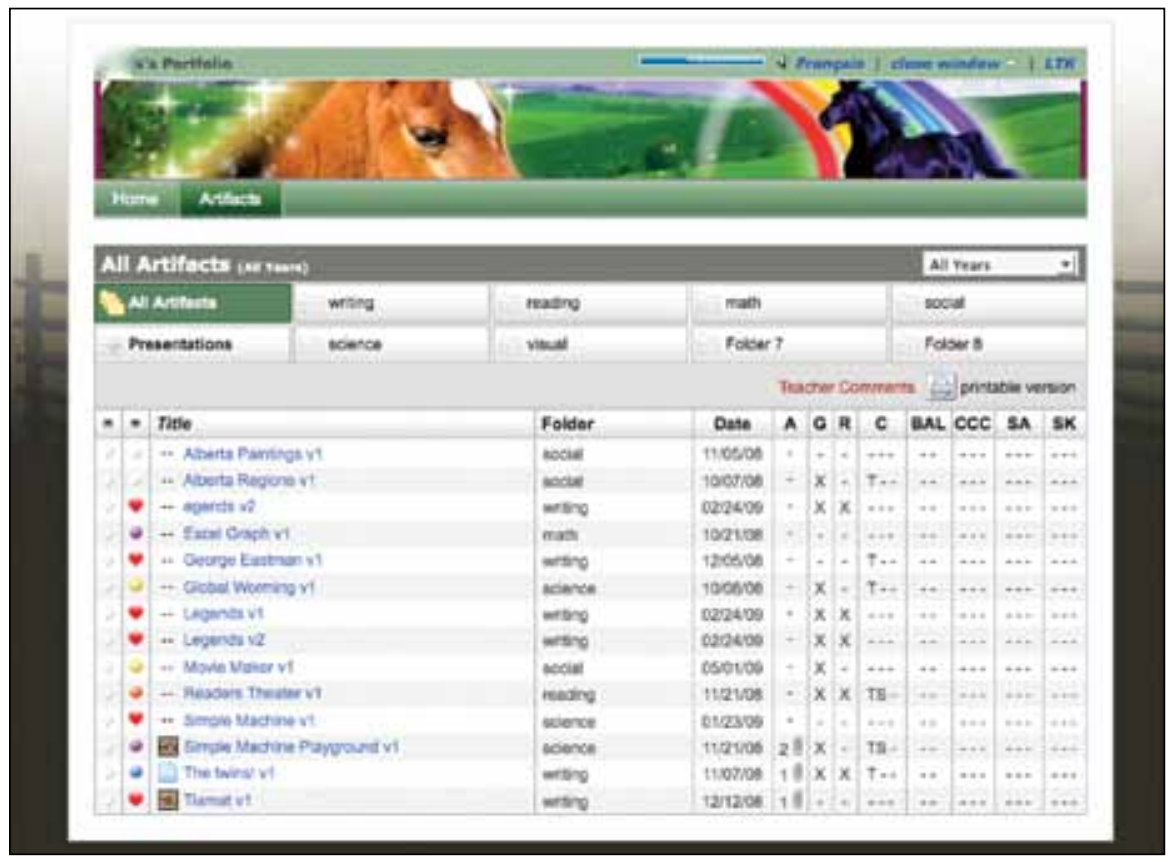

Fig. 3: Artifacts index page

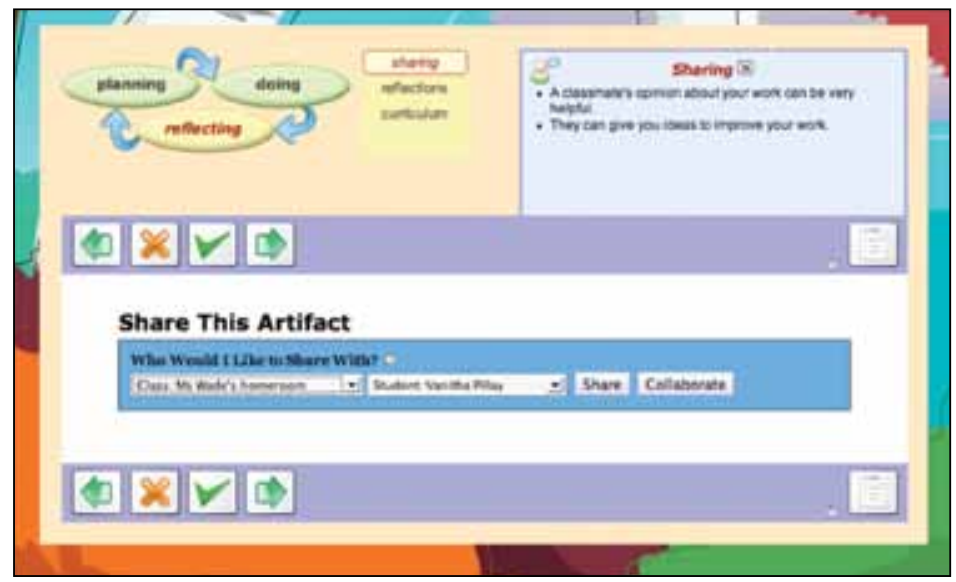

Fig. 4: Reflection screen: sharing 


\section{Scaffolding the Development of New Literacies With ePortfolios}

An EP, by definition, is a way to externalize an individual's thought processes and progressions. When beginning an ePEARL entry, the student is walked through a creation process that models a certain level of expert practice of forethought, performance, and self-reflection. Some cognitive scaffolding is made explicit at this stage, enabling students to easily address aspects or initiate practices that they may not realize are necessary or beneficial to their learning process such as reflecting on both the final content and the process. As these skills and practices are adopted and internalized by the learner, this guided step-by-step scaffolding may be turned off. ePEARL is designed to give the individual student an overview of his/her own progress. By the end of the guided process, and possibly after several drafts, the learner is ready to make a selection of works he/she would like to display by copying them to the Presentations folder.

Reflection is also actively encouraged at this point by urging learners to consider the merits of the final work, of the process, and of the contribution made to the student's awareness of him/herself as a learner. These structured processes help individual students to "develop proficiency with the tools of technology" as well as "manage, analyze, and synthesize multiple streams of simultaneous information" (NCTE, 2008). One grade four teacher commented on how working with ePEARL really helped improve her students' computer literacy skills: "The kids like using computers, so it's great in terms of computer skills. The kids had to download pictures and they had to make attachments and stuff, so it's great in terms of computer technology" (QH6). A second teacher explained how the ePortfolio helped her teach technology competencies through writing assignments:

I think their technology competencies were more of the goal than the actual writing competency, because we do a lot of writing also in class. So the kids are able to learn how to attach files, learn how to save files, learn how to go and search for things, how to go back and peer edit and use the technology as more of the tool. (QL9)

A third teacher used a readers' theatre project to help students work on their writing skills, as well as reading fluency and expression. In addition to providing a place for students to demonstrate the basic technical skills necessary to type, edit, and save a Word document, attach a file, and complete an audio recording, ePEARL helps students set goals for a new work by breaking down the task and the criteria so students can focus on the various steps involved in writing a script and presenting it to the class (Figure 5). 


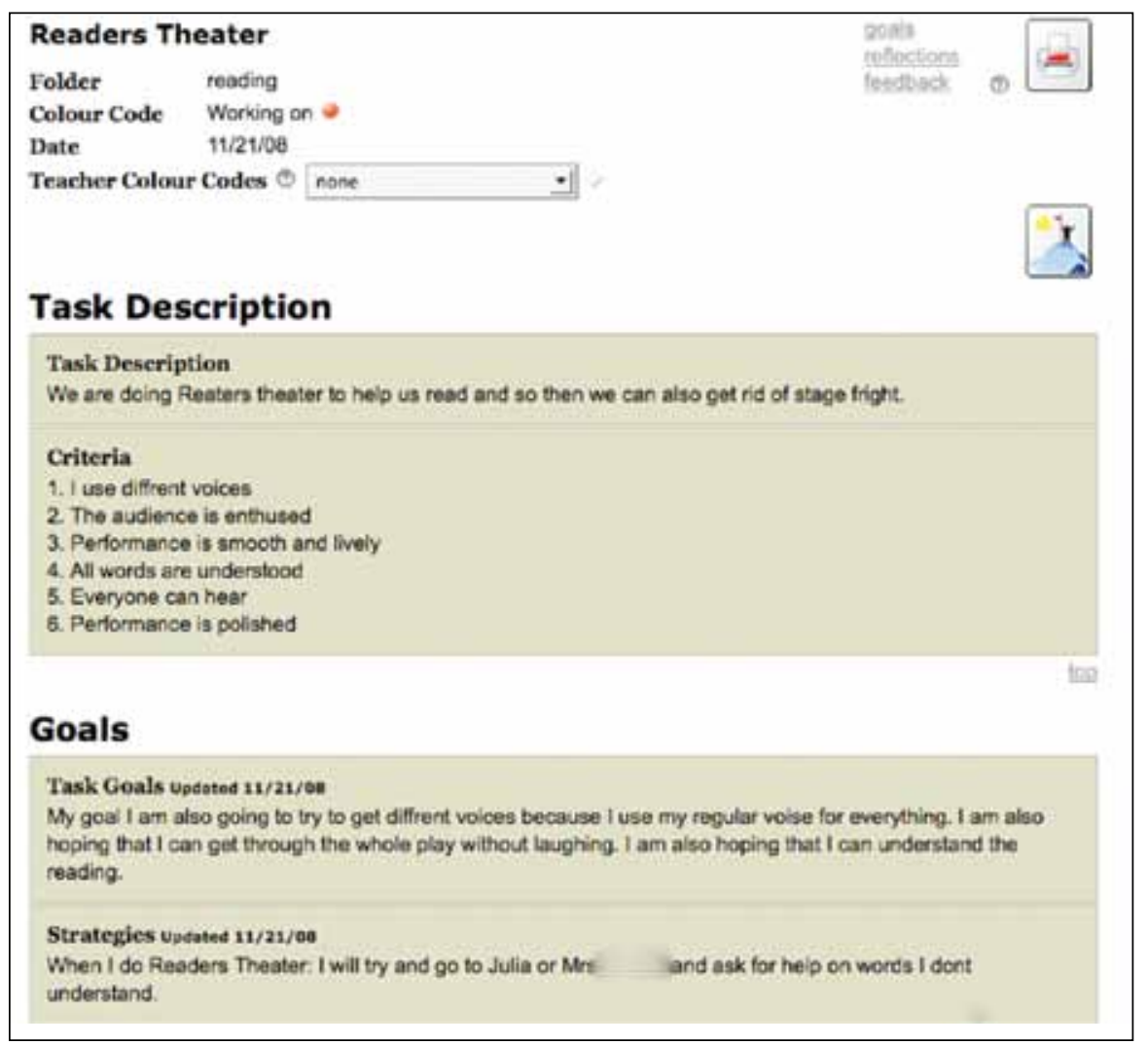

Fig. 5: Reader's theatre: planning

Particular features in ePEARL are designed to facilitate communication between individuals. The software allows students in the same class or school or across schools within a district, to comment on works in each other's portfolios. Students receiving the comments are encouraged to revise their work, incorporating those comments they feel are most helpful. Teachers are also able to comment on goals and strategies selected by the student, and thus help monitor and adjust individual student progress and understanding. Apart from facilitating the communication between teacher and students, this feature also pedagogically supports the teacher by clearly identifying where a teacher's comment may be inserted to provide the greatest help. We have provided a sample of teacher and student feedback on the readers' theatre project below (Figure 6). 


Motivation

\section{Reflections}

\section{Reflections Upanted $01 / 22 / 00$}

I think I did pretty woll Tve met all of my goals, I think I could have done better bocause I dont really look at the crowd because i get nevico, but the bad thing is that not many people could hear what I was saying, most of the people were going haa, what is she saying? When I look at the crowd I do a really wierd smile, kind of like im wierd too, Any idea's?

A couple of people said to try it out on crowds before we share with the classes. I think that my friends are really great with giving me advice. I will share everything with my friends because they can help me with everything. Im glad I know them Mrs. Said that I should meet my goals and try and have fun with your Readers Theater and see what happends, JUST HAVE FUNIt

Edit Comments $\odot$ updated

\section{Feedback}

\section{(6)}

\section{Teache} You have a lot of goals and stratogies. They are all good so lets see if we can work. together to reach them. They would make a difference to all your reading skils and your presentation skils.

\section{Edit Feedback 8}

U. Peer Feedback (5)

ei/su/us
I really liked your play
because it was realy
funny. I think it could be a
ietie louder. Try reading it
to your brother. Can he
hear you?

Fig. 6: Reader's theatre: reflecting and feedback

In this feedback, the teacher acknowledges the effort made by the student and provides encouragement and support as well as specific guidance as to how what they have learned in this assignment can translate into other literacy and communication activities. The peer feedback is also positive and encouraging regarding the oral presentation but offers very specific advice about the volume of the presenter's voice. The student providing feedback even offers the idea of reading aloud to a family member to ensure that the presenter is speaking loudly enough. Getting multiple perspectives on one's work is valuable as it allows students to synthesize various perspectives and decide which ones are most helpful for them to work on in future projects. 
ePEARL was also designed to encourage scholastic communication between students and their parents. Given that the learning environment is not limited to the classroom, practices at home are central to a student's academic success. The ePEARL software encourages parents to participate in their child's learning process by commenting on individual work as well as on the portfolio as a whole. There is also a group work component that allows students to plan, create, and reflect on projects that they have collaborated on. In addition to saving all of the group's planning steps and products, individuals are also prompted to reflect on their own contributions to the project, as well as the skills they have developed. These features help students to "build relationships with others to pose and solve problems collaboratively and cross-culturally" (NCTE, 2008). One Grade 5/6 teacher reflected on how the feedback feature helped her build a better sense of community in her classroom:

I do see that the students are able to [give] peer feedback more and accept each other a little bit better and keep their respect. There was a little bit of that bullying issue that was going on. I think that's something that we addressed because of the tool. So...how do we live in a community and respect each other are very important because it is part of our school community, [and] the ePEARL project. (QL9)

\section{Improving Teaching and Learning With ePEARL}

The teachers in this research project all commented on how working with ePEARL helped them better understand their students as learners and improved their instructional and assessment practices. One teacher noted that, "there's something about the program that really works...I think because [the students] have to be creative in terms of the writing skills but also in terms of making it visually presentable" (QH6). A second teacher reflected on how her instructional and assessment practices have improved since using ePEARL:

It just made me so aware... starting in September: here are the steps that I need to be teaching. Here are things that I need to watch for, here's the understanding I need to check on - and assessment changing so much. I like to think I was doing a fairly good job, but assessment has really changed-it is more assessment of learning, for learning, to learn...So it goes hand in hand with what we've been doing in the [school district], but it was just at the right time and I think it truly has changed my assessment practices. (AS1) 
A third teacher who worked with grades five and six talked about how she spent more time teaching her students how to provide useful feedback: "We did a lot of lessons on positive feedback, negative feedback, what is a good way to help a friend, what you find as useful feedback when someone writes you something" (QL9). The feedback and sharing feature was a popular motivational factor for many students and teachers. A grade four teacher talked about how this aspect helped improve student engagement in writing activities. She explained, "It gives them an audience to write for other than the teacher. They like sharing the work, so that's great-it motivates the kids that are sometimes really reticent about writing and I just love it" (QH6). These comments illustrate how teachers are shifting their practices in ways that engage students more effectively and promote new literacy skills. Our research team has already reported elsewhere that students who used ePEARL made significantly greater gains compared to control students in writing skills as assessed on a standardized literacy measure (Canadian Achievement Test, 4th ed.) (Meyer et al., 2010; Abrami, Venkatesh, Idan, Meyer, \& Wade, in press).

We found that teachers who used ePEARL were more likely to use technology for creative, evaluative, and informative purposes (Meyer et al., 2010). One teacher reported that she was pleased to see a change in her students' awareness of the various purposes of technology. She reported having a student tell her, "I've really realized that computers are a lot more than just a thing to go on and research." She reflected on this by adding, "I thought, wow, because we haven't really talked about that and there he is coming up with: 'this is a way for me to keep all my stuff together and watch what I'm doing' " (AS1). These data offer encouraging evidence that electronic portfolios such as ePEARL provide valuable instructional support for teachers as well as pedagogical support for students as they work to develop their 21st century literacy skills.

These teachers all demonstrated a great deal of creativity and crosscurricular approaches in their teaching. The projects that students included in their portfolios show that although teachers did primarily emphasize reading and writing activities, they also included diverse content area and media to help promote deeper and more complex understandings of the world. Some of the assignments and projects included in the EPs from these three classes are presented in Table 1 as a matrix to indicate how the various portfolio entries supported specific elements of the NCTE 21st century literacies framework. 


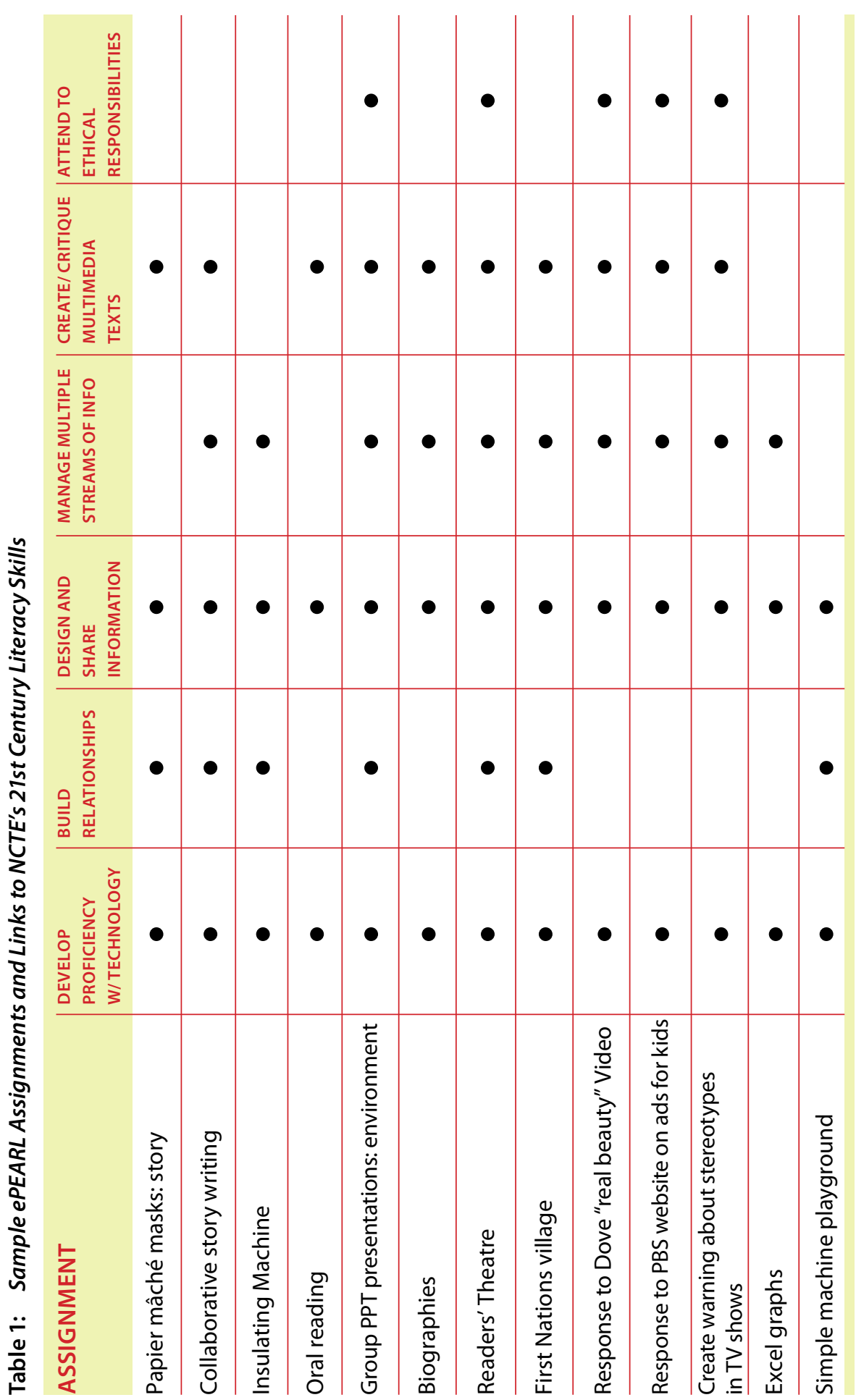


As this table demonstrates, the assignments include content from Science, History, Reading, Writing, Art, Media Literacy, Math, and Computer Technology. With each of these assignments students were developing the computer technology skills as well as at least one other area identified in the 21st century literacy program. Students were reading and critiquing various forms of media as well as creating their own texts and artifacts in individual and group projects. One teacher explained how working with ePEARL allowed students to showcase their strengths and problemsolving skills,

...they were able to do so much more: "miss, I figured out how to paste it in" or sometimes we just saw them go ahead and try, and they figured out ways to do it even before I had showed them. Which is great. They're learning from each other and they're teaching me some new stuff, too. (QL9)

The ePortfolio provides a unique medium in which students and teachers can collect, reflect, and extend on these skills. In the absence of such a rich central storage point that provides detailed information about the learning process, it would be quite difficult to show and measure student growth in these areas over time.

\section{Lessons Learned}

During this three-year research project the researchers and teachers developed new approaches to and understandings of how to best integrate the new technologies and new pedagogies associated with integrating an electronic portfolio in the elementary classroom. Some of the key lessons we have learned from this study are:

1. ePortfolios can promote creative and pedagogically sound ways to integrate new technologies in the classroom

2. Teachers reported that ePEARL improved their instructional and assessment practices

3. Teachers reported seeing positive impacts on student motivation and engagement while using ePEARL

4. ePortfolios can effectively promote each of the six elements of the 21st Century Literacies framework 
The strengths that we have observed while working with ePEARL in classrooms for the past seven years are many. We do believe in the effectiveness of an electronic portfolio to help students and teachers better understand creative and learning processes. Web 2.0 tools such as this can also help students, teachers, and families communicate and collaborate more effectively across distance and time. However, we do not claim that ePortfolios are the only way for teachers to meet the objectives outlined in the 21st Century Literacies framework. We recognize that many educators have their own creative and innovative ways of integrating various technological tools into their praxis. We also acknowledge the presence of many other exciting educational technologies. However, we are aware that many elementary teachers continue to struggle with the evolving demands of teaching these newer literacy and technology skills. ePEARL was designed in such a way as to require little technical training and the CSLP provides direct pedagogical support to the students, teachers, and school communities who have chosen to work with this tool.

Our research has demonstrated that this tool can have multiple positive impacts in classrooms, but as with any new technology in the classroom we have also documented some challenges (Meyer, Abrami, Wade, \& Scherzer, 2011). As with many technologies, teachers did experience technical issues including: computers freezing, servers crashing, limited time with and access to computers, and the need to incorporate instructional time to teach basic keyboarding skills. However, in spite of these challenges, the teachers who regularly used ePEARL were pleased with their own professional growth as well as the progress their students made. The ePEARL research and development project has resulted in the design of an effective, powerful bilingual (French-English) tool that is available at no cost to the educational community. Hopefully these success stories may inspire others to slowly integrate some new approaches to fostering 21st century literacy skills. As one teacher reported,

I'm learning so much about technology just using ePEARL, which is important. We're in a world where technology is at the front of everything, so for me, improving and learning more about it so that I can help the students is definitely my main goal. (QL9)

\section{Acknowledgments}

This research was supported by grants from the Social Sciences and Humanities Research Council of Canada, the Canadian Council on Learning, and the Fonds de recherche sur la société et la culture. 


\section{References}

Abrami, P., Venkatesh, V., Idan, E., Meyer, E., \& Wade, A.C. (in press). Using electronic portfolios to foster literacy and self-regulated learning skills in elementary students. Journal of Educational Psychology.

Abrami, P.C., \& Barrett, H. (2005). Directions for research and development on electronic portfolios. Canadian Journal of Learning and Technology, 31(3), 1-15.

Arter, J.A., \& Spandel, V. (1992). Using portfolios of student work in instruction \& assessment. Educational Measurement: Issues \& Practice, 11(1), 36-44.

Bass, W., Sibberson, F., Hayes, S., McGraw, B., \& White, S. (2010). Educators' voices on 21st century literacies. Language Arts, 87(5), 390-394.

Maclsaac, D., \& Jackson, L. (1994) Assessment processes and outcomes: Portfolio construction. New Directions for Adult and Continuing Education, 62, 63-72.

Meyer, E., Abrami, P., Wade, A., Aslan, O., \& Deault, L. (2010). Improving literacy and metacognition with electronic portfolios: Teaching and learning with ePEARL. Computers and Education, 55(1), 84-91.
Meyer, E., Abrami, P., Wade, A., \& Scherzer, R. (2011). Electronic portfolios in the classroom: Factors impacting teachers' integration of new technologies and new pedagogies. Technology, Pedagogy, and Education, 20(2), 191-207.

National Council of Teachers of English. (2008). NCTE Framework for 21st Century Curriculum and Assessment. Retrieved from http://www.ncte.org/governance/21stce nturyframework.

Wade, A., Abrami, P.C., \& Sclater, J. (2005). An electronic portfolio for learning. Canadian Journal of Learning and Technology, 31(3), 33-50.

Zimmerman, B, J. (1989). A social cognitive view of self-regulated academic learning. Journal of Educational Psychology, 81, 329-339.

Zimmerman, B. J. (2000). Attaining self-regulation: a social cognitive perspective. In Handbook of self-regulation M. Boekaerts \& P. R. Pintrich (Eds.). New York: Academic Press, 13-39.

Zimmerman, B. J., \& Tsikalas, K.E. (2005). Can computer-based learning environments (CBLEs) be used as self-regulatory tools to enhance learning? Educational Psychologist, 40(4), 267-271.

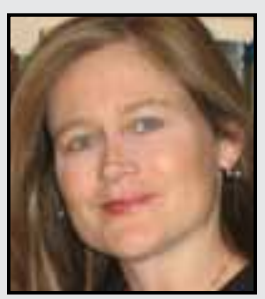

Elizabeth J. Meyer is an Assistant Professor in the School of Education at California Polytechnic State University in San Luis Obispo. She is the author of Gender, Bullying, and Harassment: Strategies to end sexism and homophobia in schools (Teachers College Press, 2009) and Gender and Sexual Diversity in Schools (Springer, 2010). She is a former high school teacher and completed her M.A. at the University of Colorado, Boulder and her PhD at McGill University in Montreal, Quebec. She blogs for Psychology Today and you can follow her on Twitter: @lizjmeyer. 


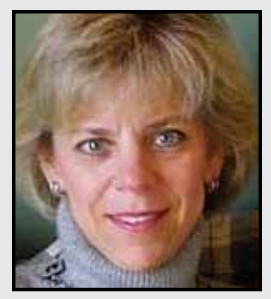

Anne Wade is Manager and Information Specialist for the Centre for the Study of Learning and Performance at Concordia University and has been a sessional lecturer in Concordia's Department of Education for 20 years. Wade is currently Coordinator of the Inquiry Strategies for the Information Society in the Twenty-first Century (ISIS-21) software development project, and has served as Coordinator of the ePEARL project since its inception over 10 years ago. She is also former President of the Eastern Canada Chapter, Special Libraries Association and the Quebec Library Association.

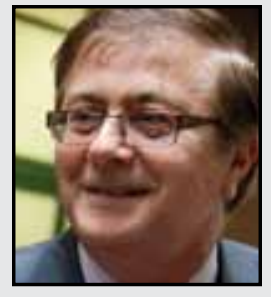

Philip C. Abrami PhD, is a Professor, University Research Chair, and the Director of Concordia University's Centre for the Study of Learning and Performance, a multi-institutional and internationally recognized educational research centre. His interests include: a) the design, development, and validation of educational software for promoting the teaching and learning of essential competencies; b) systematic reviews of educational research, particularly using quantitative methods such as meta-analysis; and c) issues in knowledge mobilization in education, particularly the high quality, sustained, and scalable implementation of educational software in classrooms worldwide. Among his numerous awards and distinctions, in 2010 he received the Canadian Education Association (CEA) Whitworth Award for Education Research.

LINK TO:

http://doe.concordia.ca/cslp/cslp_cms/ 